\title{
Germanic Language
}

National Cancer Institute

\section{Source}

National Cancer Institute. Germanic Language. NCI Thesaurus. Code C161904.

A branch of the Indo-European language family spoken natively mainly in Europe, North America, Oceania, and Southern Africa. 